\title{
A Study of Practical Use of Carbon Paste Biosensor Mechanically Reinforced by Chloroprene Rubber
}

\author{
K. J. Yoon \\ Division of Applied Sciences, Cheongiu University; Chungbuk 360-764, Korea. E-mail: kjoon@icju.ac.kr \\ Received Jine 11, 2008
}

Key Words : Chloroprene rubber, Biosensor, Enzyme electrode, Hydrogen peroxide, Peroxidase

It is essential to immobilize an enzyme on the transducer surface in order to retain its inherent bioactivity in an enzyme modified biosensor. Numerous efforts have been directed towards finding good enzyme immobilization methods over the last 30 years. Conventional methods of enzyme immobilization include physical adsorption, ${ }^{1}$ covalent bonding or cross-linking with multi-functional reagents, ${ }^{2.3}$ entrapping within conducting redox-polymer film, ${ }^{4}$ or mixing within the bulk composite of electrode materials. ${ }^{5.6}$ However, most of these methodologies are lengthy processes, and therefore both time-consuming and costly.

We have investigated several enzyme electrodes that incorporate animal or plant tissue in carbon powder for the determination of $\mathrm{H}_{2} \mathrm{O}_{2}, 7,8$

The advantages of carbon paste electrode, including low cost and simplicity of manufacturing process, are very useful to study the electrochemical properties of enzyme electrodes in a short period time. Nevertheless carbon paste electrodes remain far from practical application because its binder. silicon oil, is nonvolatile and has no mechanical stability. So a strong need for a rigid and practicable binder made us try to look for a binder possessing the mechanical property and hinted that rubber dissolved in toluene has an excellent and high robustness after solvent escape. As a result of these efforts, HRP immobilized carbon paste electrodes, which were bound by ethylene propylene diene terpolymer, polybutadiene rubber, butyl rubber and any others, were fabricated and their new possibilities for the practical use of the biosensor have been already validated and reported. ${ }^{9.10} \mathrm{CR}$ introduced in this work is known to have a good resistance to hydrocarbon oil and a high resiliency and abrasion resistance. ${ }^{11}$ With the confident hope that these physical properties of CR described above will be able to meet the requirements of a desirable binder, a biosensor bound with CR was developed by co-immobilization of HRP in a carbon powder and the investigation of its electrochemical properties was performed. The present study reports its attractive performance characteristics of CR electrode of which the construction is simple and of low cost and has good possibilities for mass production.

\section{Results and Discussion}

The characteristics of electron transfer on an electrode surface are dependent on the structure of the electrical double layer. In order to observe how the carbon-solution interface is affected by $C R$, the current transient ( $i$ is. $t$ ) of the bioelectrode was measured by potential input. Figure 1 compares the charging current decay of the CR-modified electrode with that of the widely used glassy carbon electrode as a reference, when a potential step of $-400 \mathrm{mV}$ was applied to the electrodes in $0.1 \mathrm{M} \mathrm{NaCl}$ solutions. It shows that the maximum current of the CR-modified electrode, $2.01 \mathrm{~mA}$, is much larger than that of the glassy carbon electrode, $9.0 \mu \mathrm{A}$ and that the time constant $\tau$ of the fomer electrode, $0.19 \mathrm{sec}$, is almost twice of that of the latter electrode, $0.10 \mathrm{sec}$. This means that a considerable change broke out in the structure of double layer of the carbon paste electrode and this made the biosensor have decidedly higher capacitance than that of glassy carbon electrode. It is a matter of common knowledge that the capacitance of double layer is inversely proportional to the curvature of the
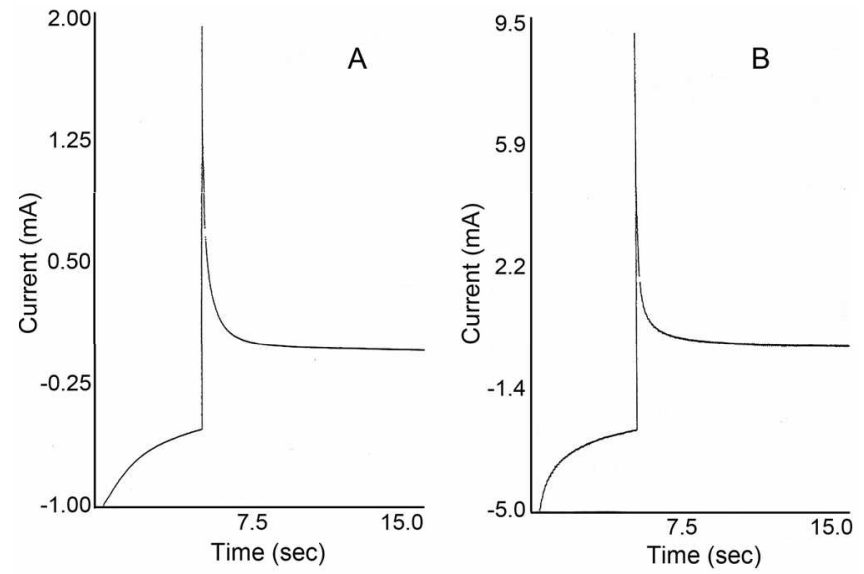

Figure 1. Charging current-time profiles of CR (A. graphite powder: $\mathrm{CR}=50: 50$. wt $/ \mathrm{wt}, 6 \mathrm{~mm}$ dia. $)$ and glassy carbon electrode $(\mathrm{B}, 3$ $\mathrm{mm}$ dia.) in $0.1 \mathrm{M} \mathrm{NaCl}$ solution. Step potential; $-400 \mathrm{mV}, \mathbf{1}_{10 \mathrm{x}} \mathrm{A}$. $0.201 \mathrm{~mA} . \tau_{\mathrm{A}}: 0.19 \mathrm{sec} .1_{1 \mathrm{ma}} \mathrm{B}: 9.0 \mathrm{uA}, \tau_{\mathrm{B}}: 0.10 \mathrm{sec}$. 


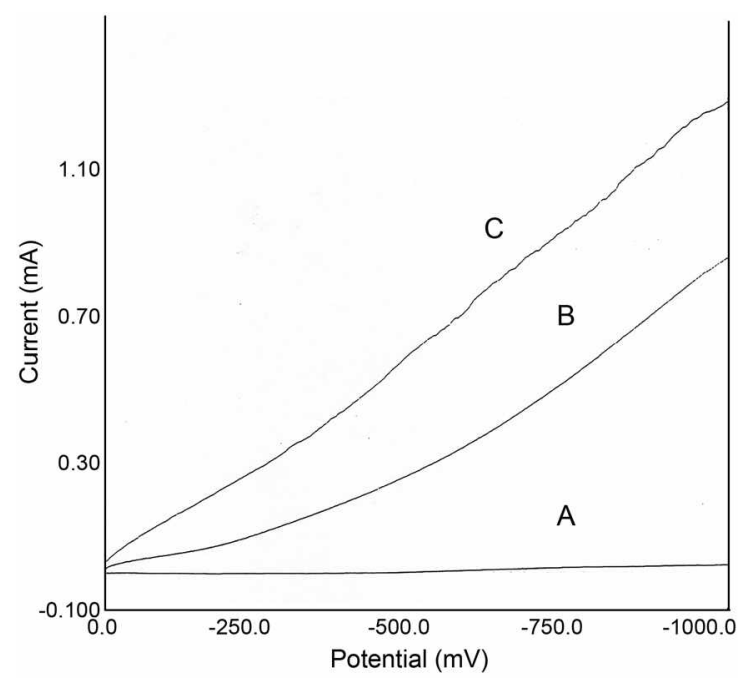

Figure 2. LSVs obtained using the carbon powder electrode with $\mathrm{CR}$ binder in a stirred $0.1 \mathrm{M} \mathrm{NaCl} 10 \mathrm{~mL}$ at the scan rate of 100 $\mathrm{mV} / \mathrm{s}$ before $(\mathrm{B})$ and after $(\mathrm{C})$ adding $200 \mu \mathrm{L}$ of $1.0 \mathrm{M} \mathrm{H}_{2} \mathrm{O}_{2}$. A is an LSV of the glassy carbon electrode in $0.02 \mathrm{M}$ hydrogen peroxide solution.

interfacial tension on the potential and the interfacial tension decreases with the amount of the adsorbed when any neutral molecule adsorbs on the surface of electrode. Here it can be seen that the decrease of interfacial tension caused by $C R$ binder in the double layer of the carbon paste electrode raised a larger condenser current than that of the glassy carbon electrode. In addition, the difference between the surface areas of electrode can be one of the causes.

Figure 2 shows three different linear sweep voltammograms (LSV). Curve A shows the electrochemical behaviour of the glassy carbon electrode in $0.02 \mathrm{M} \mathrm{H}_{2} \mathrm{O}_{2}$. Curves $\mathrm{B}$ and $\mathrm{C}$ were obtained using the $\mathrm{CR}$-modified electrode before and after adding $200 \mu \mathrm{L}$ of $1.0 \mathrm{M} \mathrm{H}_{2} \mathrm{O}_{2}$ respectively in a stirred solution. The standard reduction potentials of $\mathrm{H}_{2} \mathrm{O}$ and $\mathrm{H}_{2} \mathrm{O}_{2}$ are -0.828 and $1.77 \mathrm{~V}$, respectively. Curve $\mathrm{A}$ implies that the reduction currents which appear in curves $\mathrm{B}$ and $\mathrm{C}$ are not related to the reduction of either $\mathrm{H}_{2} \mathrm{O}$ nor $\mathrm{H}_{2} \mathrm{O}_{2}$ within the applied potential range. The relatively high reduction current in Curve B probably results from unknown constituents in the $C R$. It is reasonable to regard the current difference between Curves $B$ and $C$ as a reduction signal catalyzed by the enzyme, HRP, because the effect of the $C R$ is common to Curves $B$ and $C$. When the current difference ( $y$ in $\mathrm{mA}$ ) was plotted as a function of the applied potential $(\mathrm{x}$ in $\mathrm{mV}$ ), a straight line was obtained: $y=a+b x$, where $a=0.784$ and $b$ $=5.54 \times 10^{-4}$ with $\mathrm{R}=0.994$. It is noteworthy that this linear ohmic behavior with the applied potential is inconsistent with the previous reports. ${ }^{7,9,10}$ There is currently no theoretical explanation that can explain this type of discrepancy.

Figure 3 shows the current-time recording of the CRmodified electrode upon successive additions of $\mathrm{H}_{2} \mathrm{O}_{2}$. Immediately after an electrode potential was applied in the absence of $\mathrm{H}_{2} \mathrm{O}_{2}$ under constant stirring, the abrupt shooting of the condenser current decreased rapidly with time and gradually approached its limiting value in about 100 seconds.

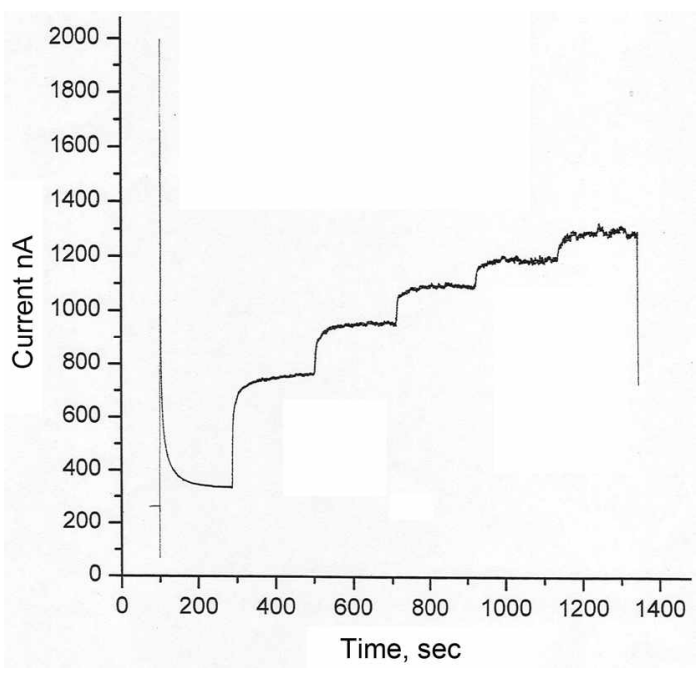

Figure 3. Amperometric response for successive adding $100 \mu \mathrm{L}$ of 1.0 $\mathrm{M} \mathrm{H}_{2} \mathrm{O}_{2}$ in $10 \mathrm{~mL}$ of electrolyte solution at $-400 \mathrm{mV}$.

When $\mathrm{H}_{2} \mathrm{O}_{2}$ was added to the electrolyte solution, the reduction current rose steeply and then stabilized. The current reached $90 \%$ of each maximum response in about 15 s. This speedy signal appearance indicates that HRP has been successfully embedded on the sensor surface and can exert its catalytic power. Thus, CR is a promising binder of carbon powder. The advantage of this hydrodynamic amperometry is that double layer charging does not enter into the measurement because the rate of mass transfer is much larger than that of diffusion.

Figure 4 is a Lineweaver-Burk plot obtained by taking the reciprocals of both accumulative signal currents and substrate concentration in Figure 3. It shows good linearity with a correlation of 0.999 . This result indicates that HRP bound on the CR-modified electrode works nomally and confirms that $\mathrm{CR}$ meets the requirements as a binder.

When $15 \mu \mathrm{L}$ of $0.1 \mathrm{M} \mathrm{H}_{2} \mathrm{O}_{2}$ solution was added to 10.0 $\mathrm{mL}$ of electrolyte, the detection limit was found to be $1.5 \times$ $10^{-4} \mathrm{M}(\mathrm{S} / \mathrm{N}=3)$. The detection limits of sol-gel HRP biosensors by Diaz et al ${ }^{12}$ and Miao ${ }^{13}$ were $6.7 \times 10^{-4} \mathrm{M}$ and $3.0 \times 10^{-6} \mathrm{M}$, respectively, suggesting that the detection limit

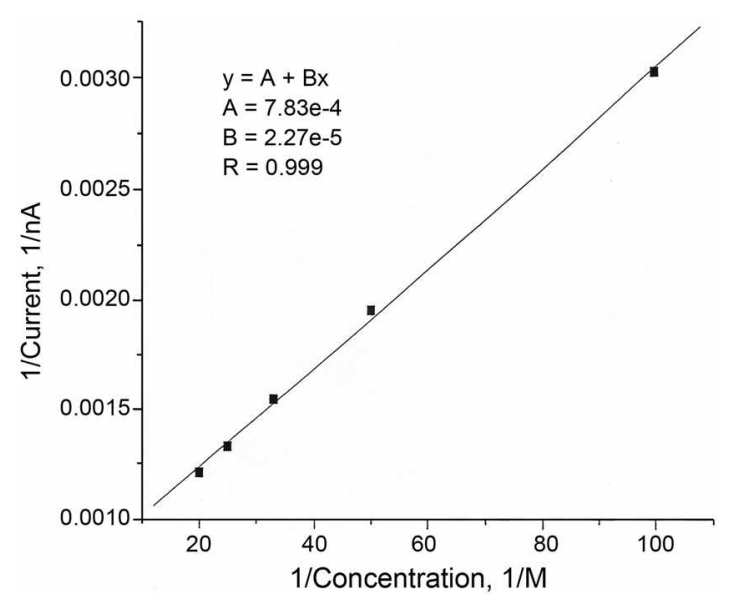

Figure 4. Lineweaver-Burk plot of the data in Figure 3. 


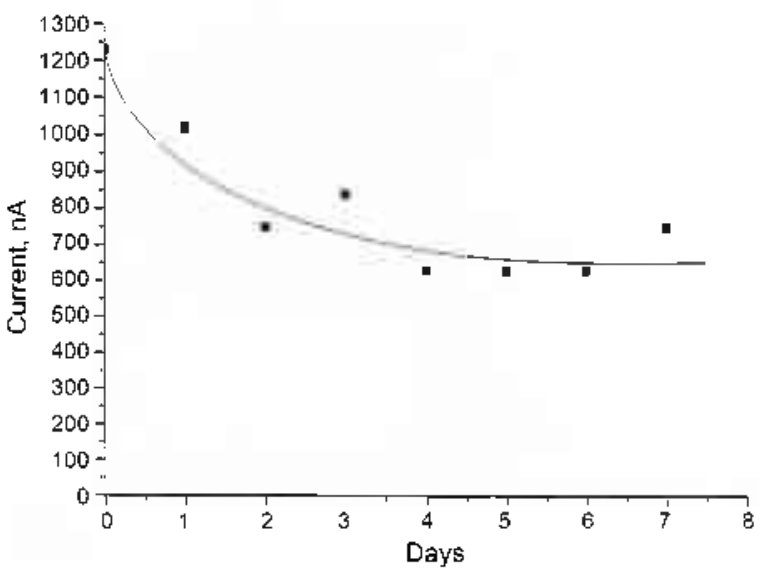

Figure 5. Stability detemination of the bioelectrode. Sensor response to $0.01 \mathrm{M} \mathrm{H} \cdot \mathrm{O}_{2}$ solution was measured over a period of 7 days. Sensor was stored in the air at $4^{\circ} \mathrm{C}$ in the dark when not in use.

of the CR-modified electrode needs to be improved further.

The requirements for practical use of a bioelectrode are the reproduciblity of the signal, long-term storage stability, and mechanical stability. There are many circumstances to denature the enzyme in the bioelectrode in the air because the energy needed to change the three-dimensional structure of an enzyme protein, $15-60 \mathrm{~kJ} / \mathrm{mol}$ is very small. Moreover, $\mathrm{H}_{2} \mathrm{O}_{2}$ can oxidize residues such as sulfhydryl in an enzyme. Furthermore microorganisms present in the air may decompose enzyme proteins on the surface of a biosensor. The decreasing trend of the signal current over time after fabrication of the biosensor in Figure 5 is the collective outcome of the above factors. The figure shows that current over 1200 nA decreases to about $50 \%$ in 2 days and then stabilizes when the electrode is stored at $4{ }^{\circ} \mathrm{C}$ in the dark.

Conclusively, a Lineweaver-Burk plot yielded a straight line and its intense signal was desirable for the practical use of this carbon paste electrode. These indicate that HRP was embedded effectively to preserve its identity and $C R$ is recommendable for binding carbon particle. A strong need for a mechanical stability of sensor was answered by CR. As a result, this study has presented a new vision for the practical use of carbon paste electrodes. But considering the durability of sensor signal, the result of the present electrode was not quite satisfactory under existing circumstances like the others. There should be a lot of efforts to circumvent this drawback for the architecture of a perfect carbon paste biosensor.

\section{Experiments}

The electrode used in this work was prepared as follows: $1.0 \mathrm{~g}$ of graphite powder was added to $1.0 \mathrm{~mL}$ of $1.0 \% \mathrm{HRP}$ (horseradish peroxidase) aqueous solution followed by drying. Carbon paste was made by mixing the HRP-coated powder with a $5 \%$ chloroprene rubber solution at a 1:1 ratio (wt/wt). The working electrode, biosensor, was made by packing this carbon paste into a $6 \mathrm{~mm}$ i.d. polyethylene tube which has ohmic contact. It was then smoothed by friction on a spatula to make a flat working surface.

The biosensor was connected to a BAS Model EPSILON (Bioanalytical System, Inc., U. S. A.) in order to obtain the linear sweep voltanmogram (LSV). The other amperometric measurements were carried out with an EG\&G Model 362 scanning potentiostat (Princeton Applied Research, U. S. A.) and its output was recorded on a Kipp \& Zonen X-t recorder (BD111, Holland). A BAS MF2052 Ag/AgCl reference electrode and a BAS MW $1032 \mathrm{Pt}$ counter electrode were used. Chloroprene rubber was CR M-30 (Denka). Toluene and graphite power ( $\leq 0.1 \mathrm{~mm}$ ) were purchased from SigmaAldrich $(\geq 99.9 \%)$ and Fluka, respectively. Hydrogen peroxide (Junsei, EP, 35\%), $\mathrm{NaCl}$ (Shinyo Pure Chem. $\geq 99.5 \%$ ) and HRP (Sigma) were used as received.

\section{References}

1. Qian, J. M.; Suo, A. L.; Yao, Y.; Jin, Z. H. Clin. Boichent. 2004, 37,155

2. Yang, Y. H.; Yang, M. H.; Wang, H.; Jiang, J. H.; Shen, G; Yu, R. Q. Sens. Actuators B 2004, 102, 162 .

3. Ghica, M. E.; Christopher, M. A. B. Anol. Chim. Acta 2005, 532 , 145.

4. Mailley, P.; Cummings, E. A.; Mailley, S.; Cosnier, S.; Eggins, B. R.; McAdans, E. Biochemistrv 2004, 63, 291.

5. Wang, B. Q.; Dong, S. J. J. Electroanal. Chem. 2000, 487, 45.

6. Liu, M. Q.; Jiang, J. H.; Feng, Y. L.; Shen, G. L.; Yu, R. Q. Chin. J. Anal. Chem. 2007, 35, 1435 .

7. Yoon, K. J. J. Kor: Chem. Soc. 2004, 48, 644.

8. Kwon, H. S.; Jin, E. H.; Yoon, K. J.; Park, Y. N. J. Kor Chem. Soc. 2005, 49, 224.

9. (a) Choi, S. Y.; Yoon, K. J. Elastomer 2006, 41, 231. (b) Yoon, K J. Elastomer 2007, 42, 112

10. (a) Yoon, K. J. Anal. Sci. \& Tech. 2007, 20, 49. (b) Yoon, K. J. . Kor: Chem. Soc. 2008, 52, 197.

11. Brydson, J. A. Rubbert Materials and Their Compoumds; Elsevier Science Publishers Ltd.: London and New York, 1988; p 210.

12. Diaz, A. N.; Peinado, M. C. R.; Minguez, M. C. T. Anal. Chim. Acta 1998, 363, 221 .

13. Miao, Y.; Tan, S. N. Ancl. Chim. Acta 2001, 437, 87 